\title{
Soil degradation, global warming and climate impacts
}

\author{
Johannes J. Feddema*, Sergio Freire \\ Department of Geography, 213 Lindley Hall, University of Kansas, Lawrence, Kansas 66045, USA
}

\begin{abstract}
A water balance model is used to assess the relative impacts of global warming and soil degradation scenarios on water resources in the future. Results indicate that overall global warming will have a more widespread and greater impact on climate change. However soil degradation could also play a significant role in water resource issues in the future. Based on the model results, wet and dry climate regions are particularly susceptible to impacts from soil degradation. In general, reduced water holding capacities will result in increased water runoff during wet periods, which will result in higher overland flow rates and reduced recharge rates to groundwater. Water lost to runoff will also increase deficits during dry periods, in effect increasing the duration and intensity of dry periods.
\end{abstract}

KEY WORDS: Climate change $\cdot$ Soil degradation $\cdot$ Africa

Resale or republication not permitted without written consent of the publisher

\section{INTRODUCTION}

Climate is affected by a number of different human impacts. Atmospheric impacts, such as alteration of the greenhouse gas concentrations are ubiquitous and have a long-term impact on the entire global climate system. Other anthropogenic impacts are less evenly distributed in both time and space. In particular, human alteration of surface conditions can alter local and microclimates. The most significant surface alterations include changes in surface albedo and surface water availability. Examples of such alterations include urban heat island effects, land-cover change and land degradation. In Africa, one relatively well-documented, large-scale human impact on surface conditions is soil degradation (Oldeman 1988, Oldeman et al. 1990, Thomas \& Middleton 1994, Williams \& Balling 1996, Middleton \& Thomas 1997). Soil degradation, and the alteration of soil conditions, typically has significant impacts on surface water balances, by reducing soil moisture holding capacities and altering soil profiles.

Although ample evidence exists of human impacts on soil degradation, actual observation and measurement of these impacts is extremely complicated (Olde-

*E-mail: feddema@ku.edu man et al. 1988, Thomas \& Middleton 1994, Williams \& Balling 1996, Middleton \& Thomas 1997). In addition, there are multiple impacts of land degradation on climate conditions (Williams \& Balling 1996). Changes due to vegetation alteration (i.e. albedo) can be relatively short term if vegetation is allowed to recover. However changes to soil structure and water holding abilities will have much longer-term impacts on climate. Bryant et al. (1990) documented significant differences in the energy balance between overgrazed lands in Mexico and control plots in the US. Bowen ratios (the ratio of sensible and latent heat fluxes) were significantly altered in periods following rain events, as overgrazed locations dried up faster that control sites. This study will demonstrate one methodology for assessing the potential large-scale impacts of soil degradation on African climates and water resources. In addition it will compare and contrast these impacts to those expected from global warming and compare impacts for different watershed regions on the continent.

\section{METHODS}

In order to make a similar comparison between projected climate change scenarios due to global warming 
and soil degradation, the experiments were conducted in the same relatively simple water balance model (Willmott 1977, Mather 1978) for the African continent. In the soil degradation experiment, soil water holding capacity changes were simulated based on observed changes in soil condition between 1951 and 1980 (GLASOD database; see Oldeman 1988, Middleton \& Thomas 1997). Similarly, global warming is simulated by altering climate input conditions. The transient HADCM2SUL model runs from the UKMET GCM model (Mitchell et al. 1995, Mitchell \& Johns 1997) were used to modify current climatologies (Legates \& Willmott 1990a,b), thereby simulating temperature and precipitation conditions for 2010-2039 or 2040-2079. Details of the model used and the exact methodology are provided elsewhere (Feddema 1998, 1999). Future scenarios of changes in soil water holding capacities are based on projections of soil degradation observations in the 1951-1980 period. In the GLASOD study soil degradation parameters are provided in terms of an impact type (e.g. water and wind erosion), and categorical estimates of the intensity and extent of that impact. These values were used to estimate a percentage reduction in soil water holding capacities. Future soil degradation scenarios are based on modifying the categorical values of soil degradation intensity and soil degradation extent in a region (Feddema 1999). It should be emphasized that the GLASOD database was not intended for this specific use and that it only provides an approximation to soil degradation issues as discussed in this study. However, this database does cover the entire African continent, and since this study is intended as an exploration of the possible impacts of soil degradation on climate change, it is a good first approximation to evaluating this problem. The soil degradation estimates are combined with a soil water holding capacity database (Dunne \& Willmott 1996) to provide estimates of water holding estimates for the specified time period.

Interactions between the data used in the study and the various models used to create the simulations are illustrated in Fig. 1. The climate scenarios are based on the precipitation and temperature climatologies developed by Legates \& Willmott $(1990 a, b)$. These data are used as model input to simulate current climate conditions. To simulate global warming, the Legates \& Willmott $(1990 \mathrm{a}, \mathrm{b})$ climatologies are modified by the projected temperature changes and relative precipitation changes based on the Hadley HADCM2SUL model runs from the UKMET GCM model (Mitchell et al. 1995, Mitchell \& Johns 1997) (see Feddema 1999 for further details). Surface parameters used in the model are soil water holding capacities, which for predegradation are represented by the Dunne \& Willmott (1996) database. These soil water holding capacities

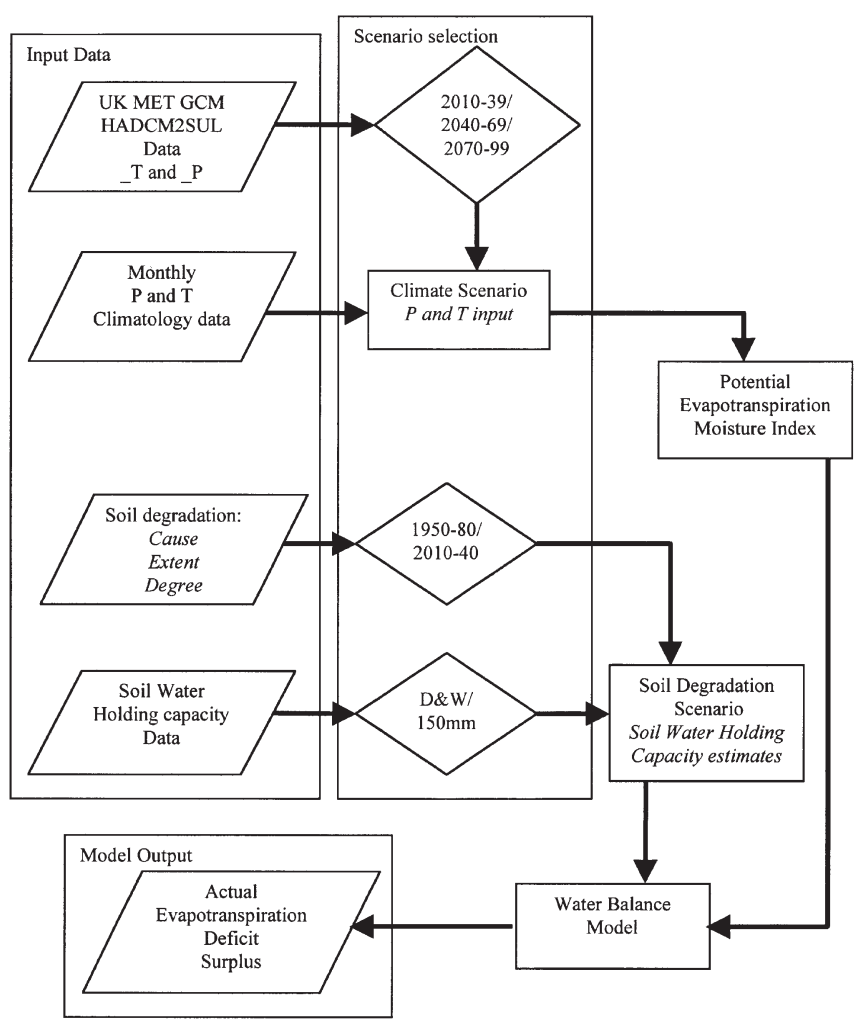

Fig. 1. Schematic of the model and data input to develop various scenarios

can then be modified using the GLASOD soil degradation factors (Feddema 1998). This methodology allows the user to simulate a number of conditions ranging from control scenarios to scenarios of global warming, soil degradation or combinations of each. Output from the water balance model includes simulated temperature and precipitation conditions for the global warming scenarios, estimates of potential and actual evapotranspiration, estimates of moisture surplus and water deficit conditions, and values of the moisture index and monthly moisture index range at each grid cell. Both model input and output data are modified and processed in a geographic information system (GIS).

\section{RESULTS AND DISCUSSION}

For illustrative purposes the results simulating conditions for 2010-2039, as compared to the 1960-1990 base period, are given here. Fig. 2 shows predegradation soil water holding capacities (Fig. 2a, based on Dunne \& Willmott 1996) and estimated percentage reduction in soil water holding capacities based on simulations for 2010-2039 (Fig. 2b, based on extrapolation of the GLASOD trends; Feddema 1999). 


\section{a) Soil Water Holding Capacity}

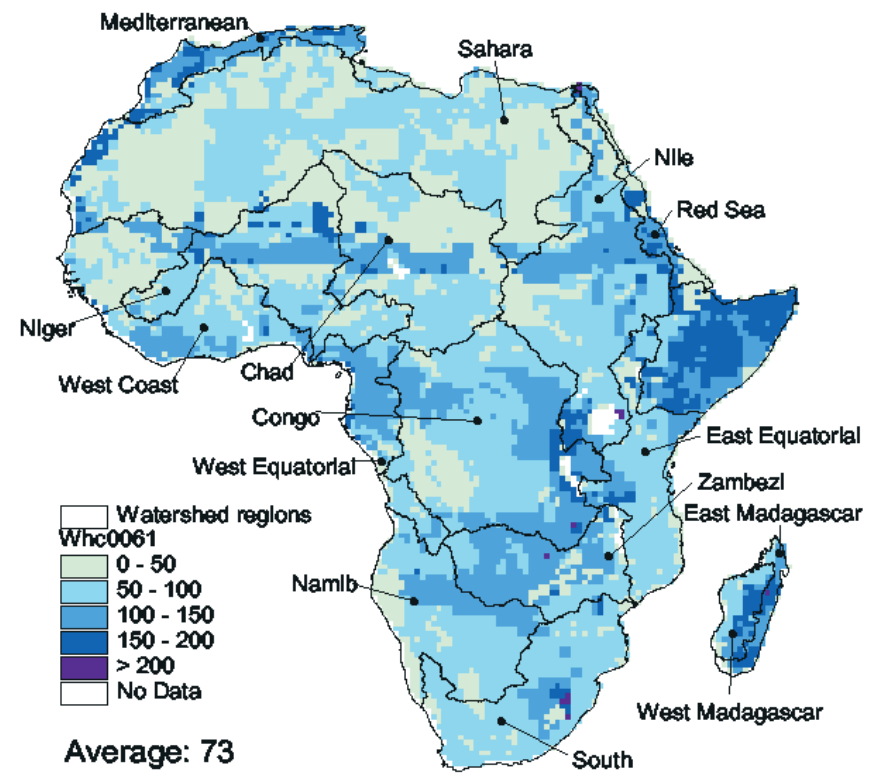

b) Percent Reduction: 2010-39

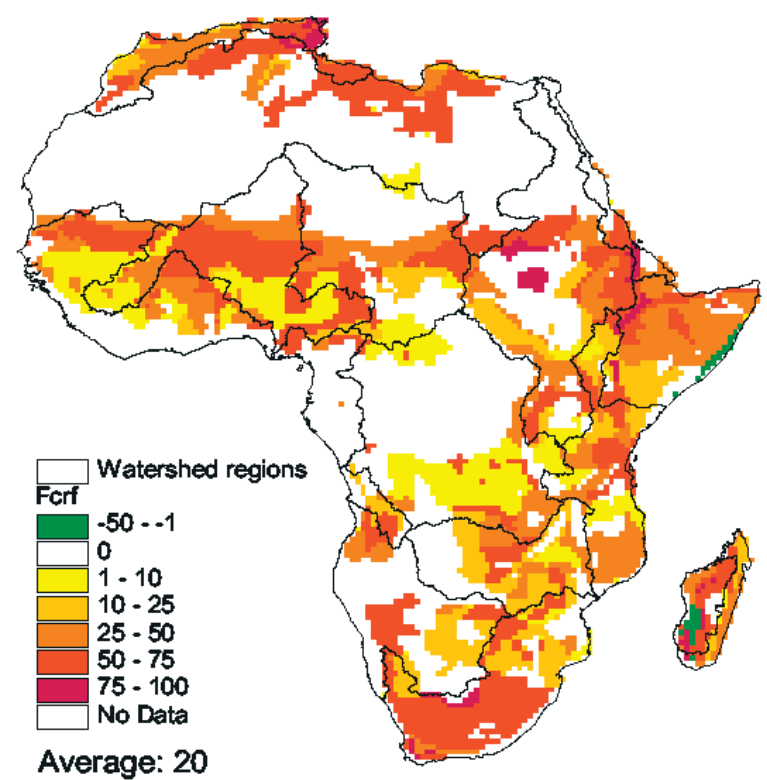

Fig. 2. (a) Soil water holding capacities used in the study (from Dunne \& Willmott 1996); (b) the simulated reduction in soil moisture holding capacities for the 2010-2039 time period (expressed as a percentage)

The global warming scenario suggests that there will be significant changes in temperature values, and precipitation and potential evapotransipration rates (Fig. 3). Average temperatures, continent wide, for the 2010-2039 period are expected to increase by $1.33^{\circ} \mathrm{C}$, resulting in a $119 \mathrm{~mm}$ increase in the potential evapotranspiration rate. At the same time, precipitation is expected to increase by $30 \mathrm{~mm}$ continent wide, resulting in a net drying of the continent. This drying will almost certainly have dramatic impacts on local agricultural and social systems. The combination of these events decreases moisture surplus conditions and the amount of water available for overland runoff, through-flow and ground water recharge (Fig. 4a,b). There will be slight increases in actual evapotranspiration over most of the continent (41 mm continent wide, Fig. 5a,b); however this increase is offset by the increase in water demand from potential evapotranspiration. This results in an overall increase in moisture deficits, and drying, across the continent (Fig. 5d,e). The impacts of global warming are fairly evenly distributed across most of the continent with the exception of a few regions, primarily in the southern portion of east and central Africa (Tanzania, Malawi and Zambia) where precipitation is expected to decrease while evapotranspiration rates increases, further exacerbating drying conditions. Large increases in precipitation are expected in the equatorial coastal zones. These precipitation increases tend to occur during rainy peri- ods, when these areas already receive adequate moisture. Therefore, these increases in water supply do little to alleviate drought conditions during the dry season, and will contribute significantly to increased surplus moisture and runoff. This could potentially be a problem for low lying areas and flood zones.

Soil degradation has no direct impact on the input climate variables (precipitation and temperature) in this model. However, in reality it does impact the disposition of energy and water availability at the surface through a number of feedback mechanisms. In general the impacts of soil degradation result in a decrease in soil water holding capacities. This means that soils can absorb less water during rain events and increases surplus water conditions. Similarly, the reduced water availability is a liability during dry periods, when less moisture is available for evapotranspiration purposes. Therefore, in most locations affected by soil degradation, moisture surpluses are increased, resulting in equivalent decreases in actual evapotranspiration and increases in water deficits (about $7 \mathrm{~mm}$ continent wide, Fig. 4c). In terms of local impacts this means that during high rainfall periods runoff will decrease and that ground water recharge will be reduced during this period; more water is lost from the system with increased runoff. In addition, less water will be available from the soil during subsequent dry periods, with resultant decreases in actual evapotranspiration and increased water deficits. 

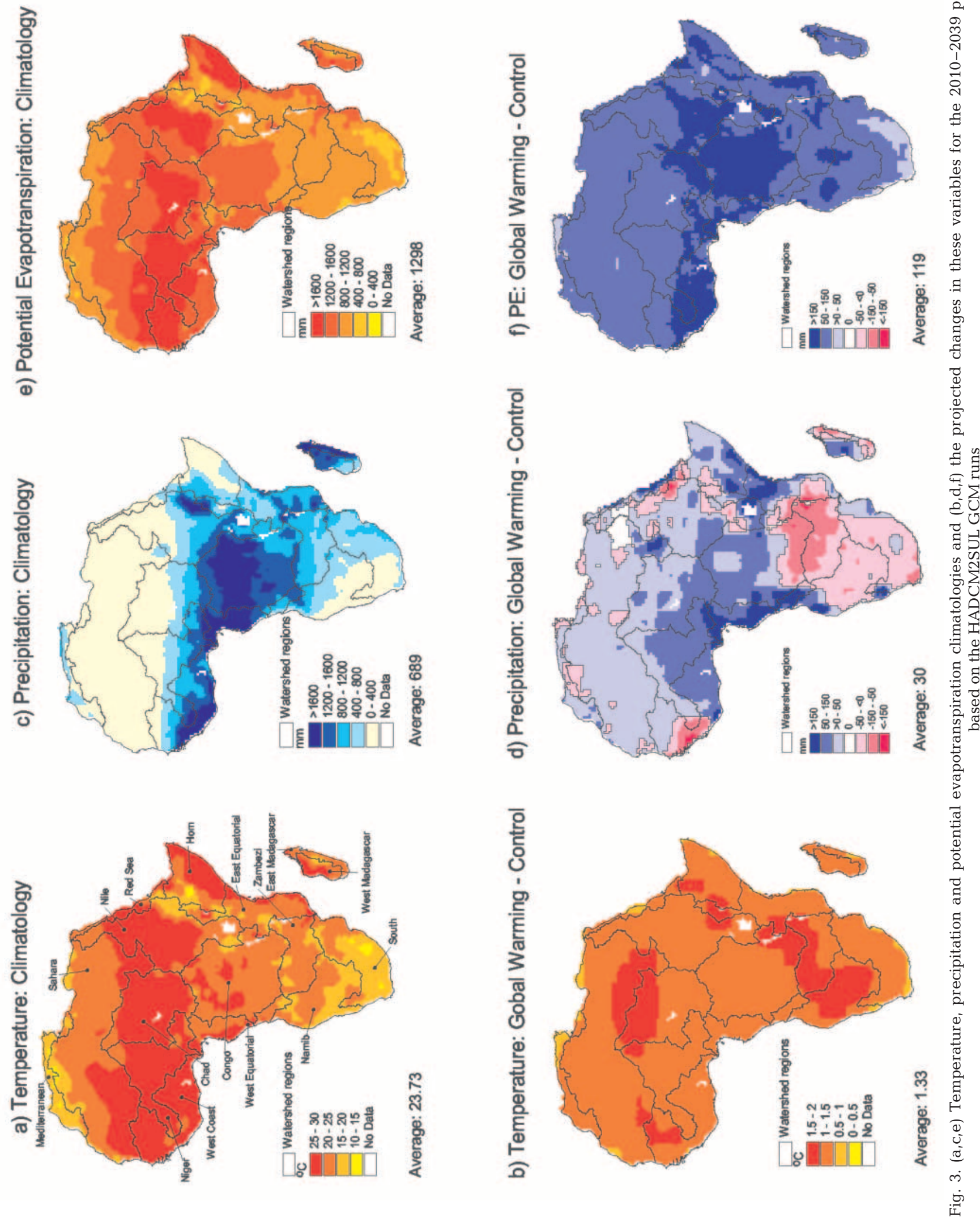
Table 1 shows the projected increases/decreases in moisture surplus, actual evapotranspiration and soil moisture deficit for each major watershed due to global warming, soil degradation and combined conditions. All major watersheds are affected by global warming.
While the general trend is towards a drying in most locations, there are significant differences in watershed level responses to both global warming and human soil degradation. Different responses are dependent on a number of factors including the timing and distribu- a) Climatology: Surplus

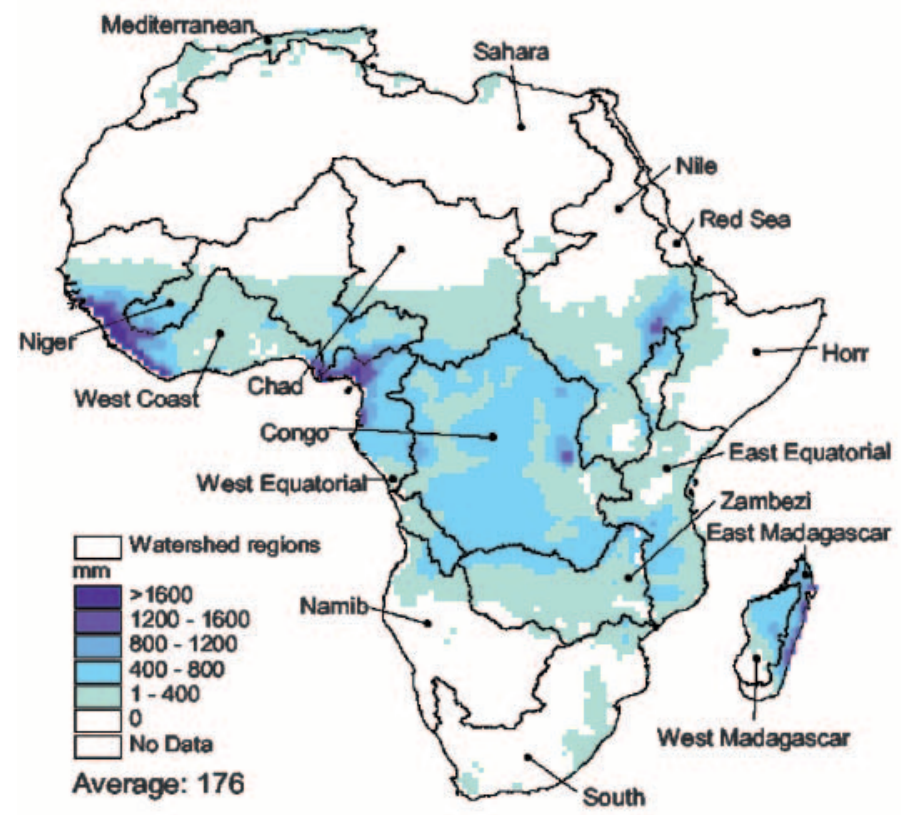

c) Surplus: Soil Degradation - Control

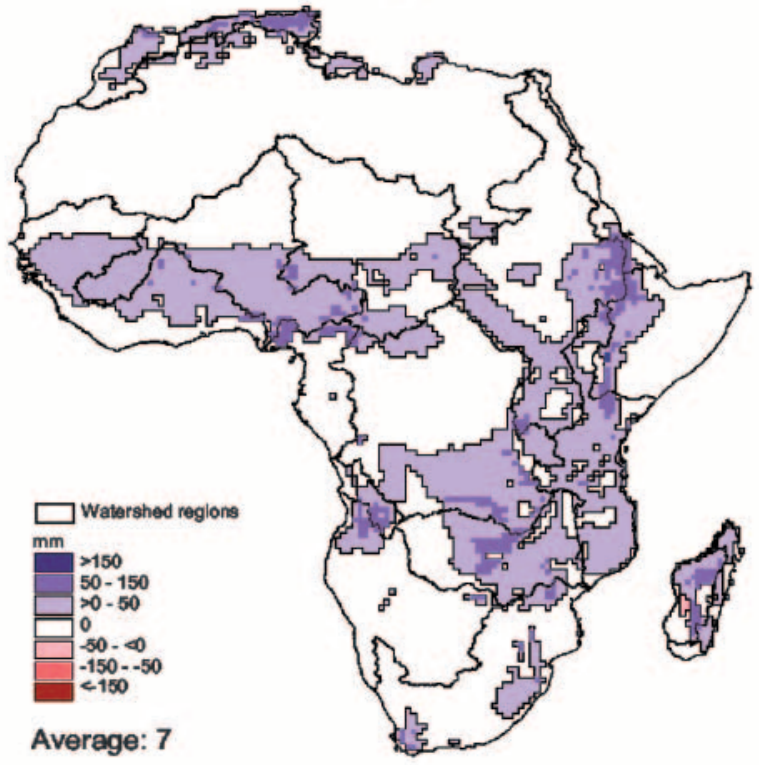

b) Surplus: Global Warming - Control

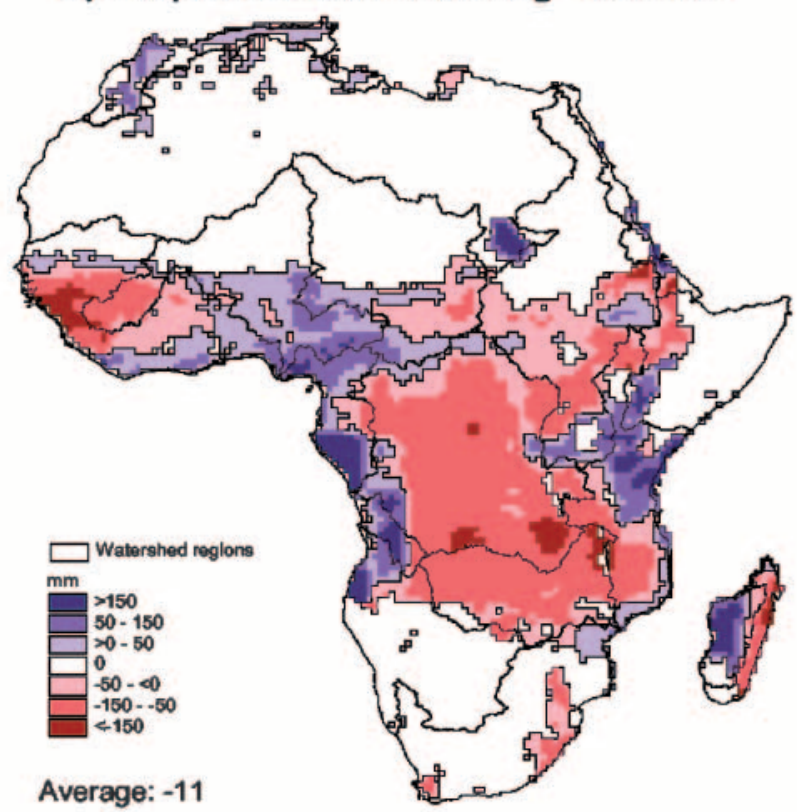

d) Surplus: Combined Scenarios - Control

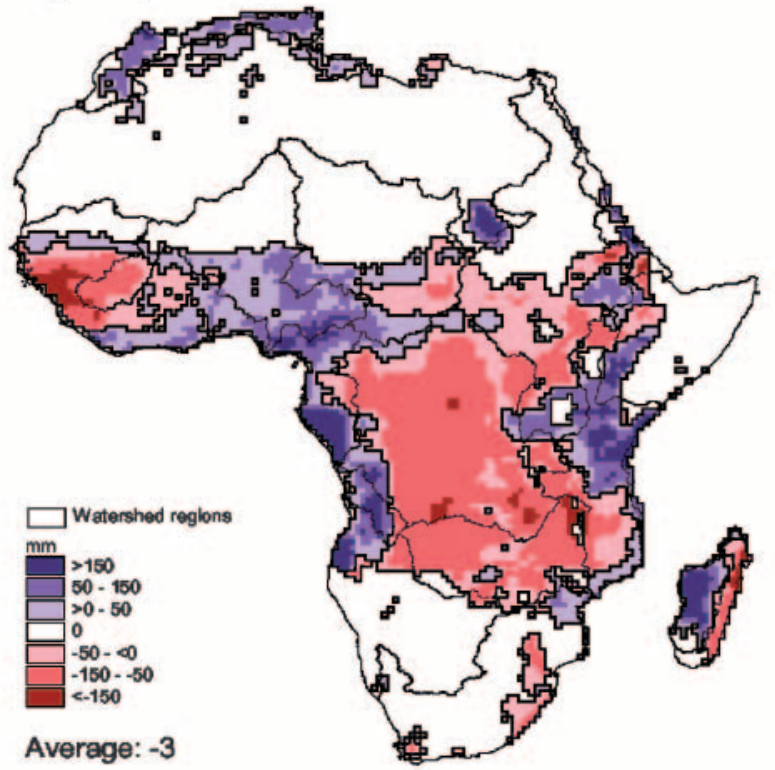

Fig. 4. (a) Surplus moisture climatology, (b) simulated changes from the HADCM2SUL GCM model runs for the 2010-2039 period; (c) simulated changes from projected soil degradation impacts; and (d) the combined impacts of global warming and soil degradation 
a) Actual Evapotranspiration: Climatology

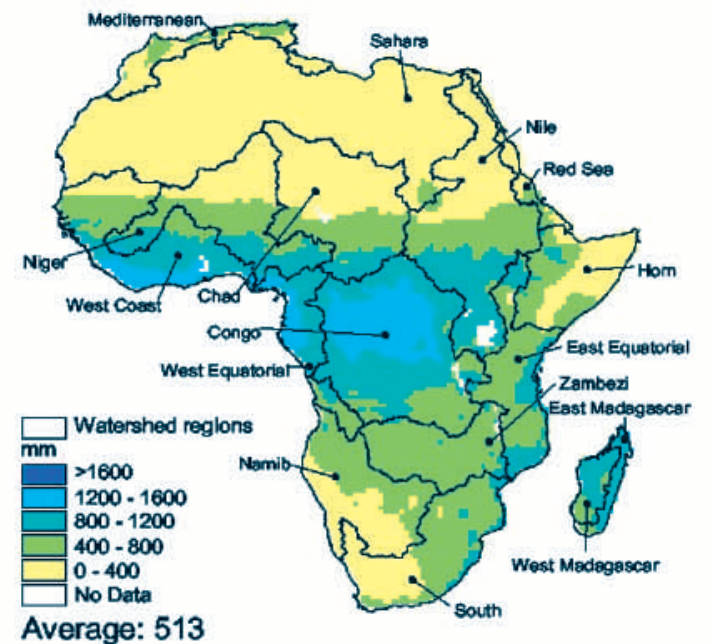

b) AE: Global Warming - Control

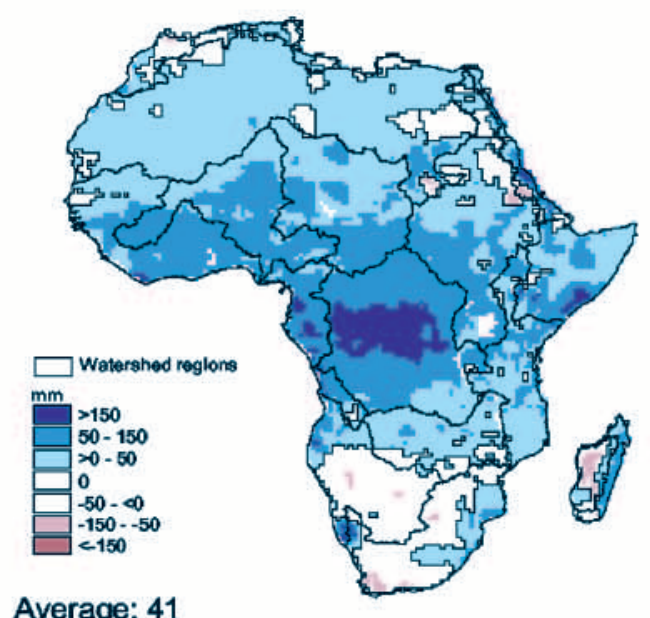

Average: $\mathbf{4 1}$

c) AE: Combined Scenarios - Control

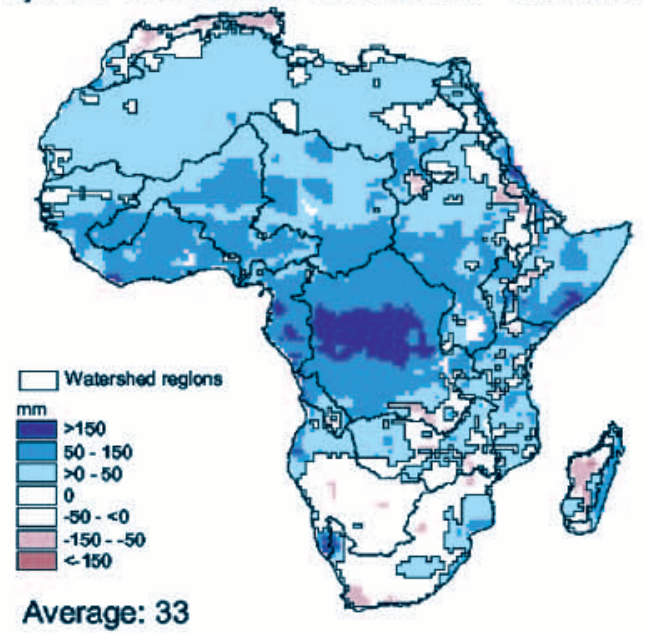

d) Deficit: Climatology

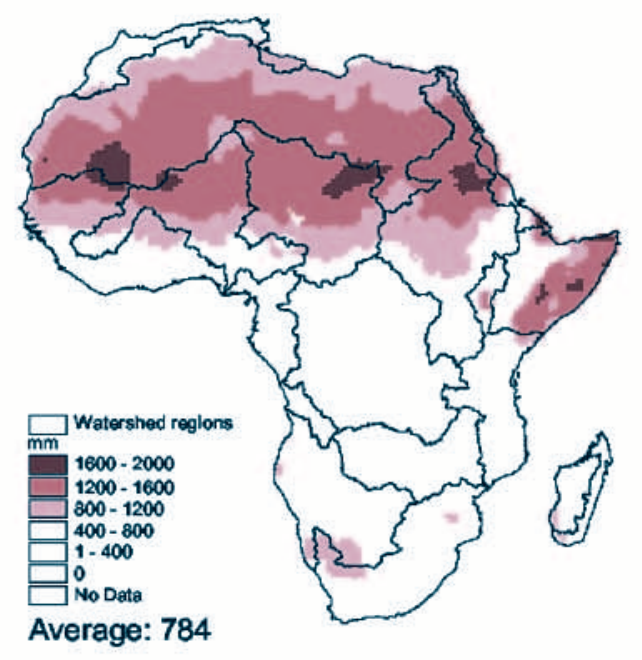

e) Deficit: Global Warming - Control

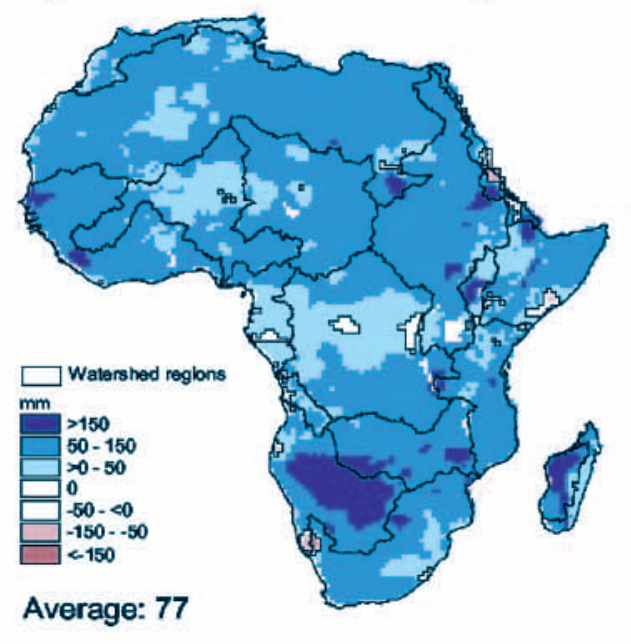

f) Deficit: Combined Scenarios - Control

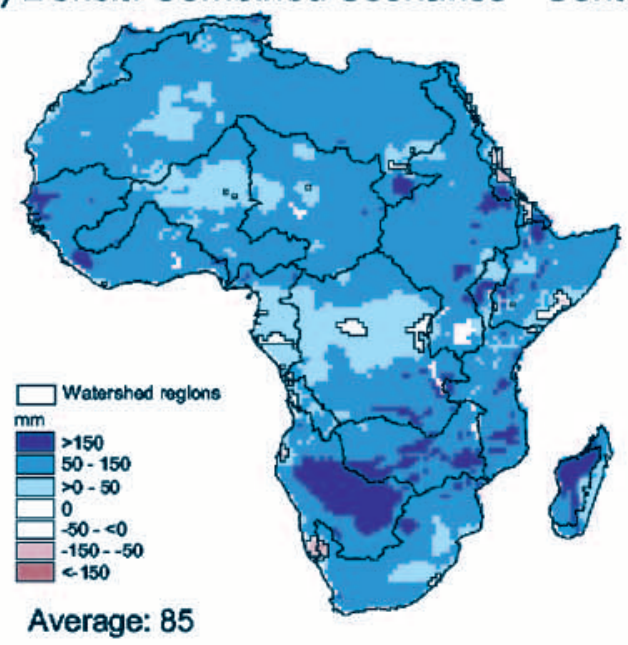

Fig. 5. (a,d) Actual evapotranspiration and moisture deficit climatologies, (b,e) projected changes due to global warming alone and $(\mathrm{c}, \mathrm{f})$ the combined effects of global warming and soil degradation 
tion of rainfall conditions. This is especially noticeable in the Mediterranean watershed, where overall potential evapotranspiration rates are significantly increased while precipitation rates are also marginally increased. However, because precipitation primarily falls in the cool winter period, there is a slight increase in surplus during that time. This is combined with severe effects from soil degradation and an inability of soils to absorb excess rainfall; the net result of global warming and soil degradation is a significant increase in water surplus over the year, projecting increased river runoff conditions. At the same time, the reduced soil water holding capacities result in less water availability during dry periods. This exacerbates the drying due to large increases in water demand under global warming conditions in the dry summer period. The net result is an increased moisture deficit during the summer dry periods, translating to longer and more intense dry periods. Similarly, other watershed statistics have to also be interpreted cautiously; for example, the Niger basin receives a significant portion of its water from a relatively small area of the total watershed. Human impacts in this critical region can skew the overall statistics for the river basin in terms of predicted changes in runoff and water resources.

The impacts of both global warming and soil degradation were also evaluated for different moisture regions on the continent (Table 2 ; moisture regions are based on those defined by Middleton \& Thomas 1997). The very driest regions appear to suffer relatively little from the soil degradation scenarios. This is largely because of limitations of the model, which assumes no surplus moisture until the soil reservoir is filled. Overall the global warming scenario projects significant increases in moisture deficits and drying conditions. With respect to moisture surplus and projected river flows, the scenarios are remarkably balanced in their impacts. In part because of the seasonal nature of rainfall and the intensification of these rains in the global warming scenario, and because of the increased flow

Table 1. Relative water balance changes by major watershed regions. Values indicate changes from current conditions for temperature $(T)$, potential evapotranspiration $(P E)$, precipitation $(P)$ and moisture index values $\left(I_{\mathrm{m}}\right)$ for the global warming scenario from the HAD2SUL runs (GW), Soil Degradation scenarios (Soil Deg) and Combined scenarios (Comb). Units are ${ }^{\circ} \mathrm{C}$ for temperature and $\mathrm{mm}$ for all other variables

\begin{tabular}{|c|c|c|c|c|c|c|c|c|c|c|c|c|c|}
\hline \multirow{2}{*}{ Watershed } & \multirow{2}{*}{$\begin{array}{c}T \\
\text { GW }\end{array}$} & \multirow{2}{*}{$\begin{array}{c}P E \\
\text { GW }\end{array}$} & \multirow{2}{*}{$\begin{array}{c}P \\
\text { GW }\end{array}$} & \multirow{2}{*}{$\begin{array}{c}I_{\mathrm{m}} \\
\mathrm{GW}\end{array}$} & \multicolumn{3}{|c|}{ Surplus } & \multicolumn{3}{|c|}{ Actual evapotranspiration } & \multicolumn{3}{|c|}{ Deficit } \\
\hline & & & & & Soil Deg & GW & Comb & Soil Deg & GW & Comb & Soil Deg & GW & Comb \\
\hline Mediterranean & 1.16 & 65 & 18 & -0.01 & 24 & 15 & 36 & -24 & 3 & -19 & 24 & 62 & 84 \\
\hline Sahara & 1.36 & 89 & 15 & 0.01 & 0 & 3 & 3 & 0 & 12 & 12 & 0 & 77 & 78 \\
\hline West Coast & 1.34 & 151 & 35 & -0.04 & 8 & -23 & -17 & -8 & 57 & 51 & 8 & 93 & 99 \\
\hline Niger & 1.32 & 127 & 72 & 0 & 10 & 8 & 14 & -10 & 64 & 57 & 10 & 63 & 69 \\
\hline Chad & 1.39 & 125 & 52 & 0.01 & 5 & 1 & 5 & -5 & 51 & 48 & 5 & 74 & 78 \\
\hline Nile & 1.36 & 127 & 25 & -0.03 & 10 & -12 & -5 & -10 & 37 & 30 & 10 & 90 & 97 \\
\hline Red Sea & 1.2 & 102 & 38 & 0.01 & 13 & 0 & 5 & -13 & 38 & 32 & 13 & 64 & 70 \\
\hline Horn & 1.3 & 128 & 59 & 0.01 & 11 & 2 & 12 & -11 & 57 & 47 & 11 & 71 & 81 \\
\hline West Equatorial & 1.18 & 141 & 191 & 0.01 & 13 & 87 & 93 & -13 & 104 & 98 & 13 & 37 & 43 \\
\hline Congo & 1.3 & 166 & 34 & -0.09 & 8 & -75 & -68 & -8 & 109 & 102 & 8 & 57 & 64 \\
\hline East Equatorial & 1.32 & 128 & 45 & -0.04 & 18 & 4 & 20 & -18 & 42 & 26 & 18 & 87 & 103 \\
\hline Namib & 1.48 & 118 & 6 & -0.04 & 4 & 14 & 17 & -4 & -8 & -10 & 4 & 126 & 128 \\
\hline Zambezi & 1.48 & 128 & -63 & -0.14 & 17 & -78 & -65 & -17 & 15 & 2 & 17 & 112 & 126 \\
\hline West Madagascar & 1.13 & 118 & 59 & -0.03 & 32 & 79 & 99 & -32 & -20 & -40 & 32 & 139 & 159 \\
\hline East Madagascar & 1.14 & 109 & -26 & -0.07 & 7 & -74 & -64 & -7 & 48 & 38 & 7 & 62 & 71 \\
\hline South & 1.19 & 76 & -10 & -0.05 & 5 & -5 & -2 & -5 & -5 & -8 & 5 & 80 & 83 \\
\hline
\end{tabular}

Table 2. Relative water balance changes by aridity zones (as described by Middleton \& Thomas 1997). Values are indicated for changes from current conditions for temperature $(T)$, potential evapotranspiration $(P E)$, precipitation $(P)$ and moisture index values $\left(I_{\mathrm{m}}\right)$ for the Global Warming Scenario from the HAD2SUL runs (GW), Soil Degradation scenarios (Soil Deg) and Combined scenarios (Comb). Units are ${ }^{\circ} \mathrm{C}$ for temperature and $\mathrm{mm}$ for all other variables

\begin{tabular}{|c|c|c|c|c|c|c|c|c|c|c|c|c|c|}
\hline \multirow[t]{2}{*}{ Aridity zone } & \multirow{2}{*}{$\begin{array}{c}T \\
\text { GW }\end{array}$} & \multirow{2}{*}{$\begin{array}{c}P E \\
\text { GW }\end{array}$} & \multirow{2}{*}{$\begin{array}{c}P \\
\text { GW }\end{array}$} & \multirow{2}{*}{$\begin{array}{c}I_{\mathrm{m}} \\
\mathrm{GW}\end{array}$} & \multicolumn{3}{|c|}{ Surplus } & \multicolumn{3}{|c|}{ Actual evapotranspiration } & \multicolumn{3}{|c|}{ Deficit } \\
\hline & & & & & Soil Deg & GW & Comb & Soil Deg & GW & Comb & Soil Deg & GW & Comb \\
\hline Hyper arid & 1.40 & 91.16 & 13.44 & 0.01 & 0.00 & 0.06 & 0.06 & 0.00 & 13.38 & 13.38 & 0.00 & 77.78 & 77.78 \\
\hline Arid & 1.32 & 98.34 & 29.60 & 0.01 & 0.25 & 1.73 & 2.20 & -0.25 & 27.87 & 27.40 & 0.25 & 70.47 & 70.94 \\
\hline Semi arid & 1.33 & 121.69 & 27.32 & -0.02 & 5.64 & 5.68 & 10.08 & -5.64 & 21.63 & 17.24 & 5.64 & 100.05 & 104.45 \\
\hline Dry subhumid & 1.30 & 135.60 & 34.63 & -0.03 & 10.00 & -3.90 & 4.37 & -10.00 & 38.53 & 30.26 & 10.00 & 97.07 & 105.34 \\
\hline Other & 1.30 & 138.69 & 40.47 & -0.07 & 15.30 & -26.03 & -14.38 & -15.31 & 66.50 & 54.85 & 15.31 & 72.20 & 83.85 \\
\hline
\end{tabular}


rates with reduced soil water holding capacities, both scenarios increase moisture surplus conditions in semiarid environments. At the same time the remaining part of the year can expect increased moisture deficits for reasons similar to those in the Mediterranean summer periods.

\section{CONCLUSIONS}

From this analysis it is clear that global warming will affect all regions of Africa and that it is likely to cause major impacts on the regional water resources. However, in many places these impacts will be minimal on human populations because of the extensive desert areas with very low human populations. Results from the soil degradation scenario are generally much less severe, but can be equally detrimental in some selected regions, particularly those semi-arid regions where water is already a limiting factor. In particular, the impacts of soil degradation on water surplus can be severe as the effects of global warming. By increasing surplus and reducing infiltration of water, groundwater recharge and soil moisture during dry periods will be reduced. However, compared to global warming, the impacts from soil degradation will be much less widespread. These results indicate that the impacts from both of these scenarios can have significant impacts on the availability of water resources and on river flow regimes. Relatively densely populated regions of the continent with wet and dry climates, especially in the central-southeastern part of the continent, are most affected. In this region, agricultural productivity could be severely limited under these simulated conditions.

Several other factors will also likely play a role in future water resources and water quality on the African continent. With rapid urbanization, water quality is likely to decline, and the reduced impermeability of urban areas will create soil degradation conditions much like and even more severe than those simulated here. Future work will need to evaluate these impacts in linked energy and water balance models to evaluate the impacts of feedbacks associated with soil degradation and should include urbanization as part of that effort.

Acknowledgements. This work was partly funded by the UCLA Academic Senate and NCAR. Thanks go to C. J. Willmott, K. A. Dunne and D. R. Legates for providing the climatology and soil data and UNEP/GRID program for providing the GLASOD data.

\section{LITERATURE CITED}

Bryant NA, Johnson LF, Brazel AJ, Balling RC, Hutchinson CF, Beck LR (1990) Measuring the effect of overgrazing in the Sonoran desert. Clim Change 17:243-264

Dunne K, Willmott CJ (1996) Global distribution of plantextractable water capacity of soil. Int J Climatol 16:841-859

Feddema JJ (1998) Estimated impacts of soil degradation on the African water balance and climate. Clim Res 10: 127-141

Feddema JJ (1999) Future African water resources: interactions between soil degradation and global warming. Clim Change 42(3):561-596

Legates DR, Willmott CJ (1990a) Mean seasonal and spatial variability in gauge-corrected global precipitation. Int $\mathrm{J}$ Climatol 10:111-127

Legates DR, Willmott CJ (1990b) Mean seasonal and spatial variability in global surface air temperature. Theor Appl Climatol 41:11-21

Mather JR (1978) The climatic water budget in environmental analysis. Lexington Books, Lexington

Middleton NJ, Thomas DSG (1997) World atlas of desertification, 2nd edn. UNEP, Geneva

Mitchell JFB, Johns TC (1997) On modification of global warming and sulphate aerosols. J Clim 10(2):245-267

Mitchell JFB, Johns TC, Gregory JM, Tett S (1995) Climate response to increasing levels of greenhouse gases and sulphate aerosols. Nature 375:501-504

Oldeman LR (ed) (1988) Guidelines for general assessment of the status of human-induced soil degradation. Working paper and preprint 88/4. ISRIC, Wageningen

Oldeman LR, Hakkeling RTA, Sombroek WG (1990) World map of the status of human-induced soil degradation. An explanatory note. ISRIC/UNEP, Wageningen

Thomas DSG, Middleton NJ (1994) Desertification: exploding the myth. John Wiley \& Sons, Chichester

Williams MAJ, Balling RC (1996) Interactions of desertification and climate. For WMO/UNEP, Arnold Press, London

Willmott CJ (1977) WATBUG: a FORTRAN IV algorithm for calculating the climatic water budget. Publ Climatol 50(1)

Proofs received from author(s): July 25, 2001 